\title{
Analysis of Headway in Traffic Streams on the Minor Leg of an Intersection
}

\author{
Adewumi, E ${ }^{1}$ and Allopi, $\mathrm{D}^{2}$ \\ Durban University of Technology ${ }^{\text {Iand } 2}$ P. O. Box 1334, Durban, 4000 South Africa
}

\begin{abstract}
An increase in the number of road users and pedestrians lead to increasing demand on the facilities and eventual inconvenience and delays. This study evaluated the response time of drivers on the minor leg of the Challenge Intersection in Ilorin because of the significance of the minor traffic stream on the capacity analysis or design of traffic merging at the major leg.The method employed was basically manual whereby stopwatches were used to measure the response time of drivers. The response time of each driver in a traffic stream was taken in relation to theirrespective positions in the queue from which the headways were calculated.The headway for a car to stop is more than the headway to move as indicated in tables 1.0 and 1.1. The mean and the standard deviation for the headway to stop and move were also determined.

Keywords: Traffic warden, perception-reaction time, minor leg, traffic stream, intersection
\end{abstract}

Submitted date 14 May 2013

Accepted Date: 18 May 2013

\section{Introduction}

An increase in the number of road users and pedestrians lead to increasing demand on the facilities and eventual inconvenience and delays. The proper way of studying traffic streams or flows should be adopted at intersections and most especially in areas where stopped delays are more pronounced. Thisleads to traffic characteristics like poor headways, forced flows, delays and queues (Garber and Hoel, 1999)

The main aim of this paper was to determine the headway based on the response time of the drivers to stop and move to the traffic warden's signal at Challenge urban intersection. An intersection is the general area where two or more highways join or cross; including the roadway and roadside facilities for traffic movements within each highway radiating from an intersection, forming part of it is an intersection leg. Intersections differ in complexity from a simple intersection which has only two roads crossing angle to each other, to a more complex intersection where three or more roads cross within the same area. It can be in the form of grade separated without ramps, grade separated with ramps (commonly known as interchanges) and at grade intersection (AASHTO, 2001).

\section{Traffic Stream Characteristics}

Traffic volume is the number of pedestrians or vehicles passing a point on a lane, roadway or other traffic way during some time interval, often one hour, expressed in vehicles, bicycles or persons per hour. On a roadway, the volume of traffic fluctuations widens with time. Flow is the movement of traffic; it may be in terms of pedestrians and vehicles (Smith, 2002).

Time headway is the time usually in minutes between the passing of the front ends of successive transit units moving along the same lane or track in the same direction (Hobbs, 1994). A queue is a line of vehicles, bicycles or pedestrians waiting to be served by the system in which flow rate from the front of the queue are usually considered part of the queue(Akcelik, 1999).

\section{Movement Time}

Once a response is selected, the responder must perform the required muscle movement. For example, it takes time to lift the foot off the accelerator pedal, move it laterally to the brake and then to depress the pedal. Several factors affect movement times. In general, the more complex the movements, the longer the movement time it takes. Finally, Yerkes-Dodson Law states that high emotional arousal, which may be created by emergency, speeds or gross motor movements and pairs fine detailed movements(Vonk, 2007). Mechanical devices take time to actuate, even after the responder has acted. For example, a driver stepping on the brake pedal does not stop the car immediately. Instead, the stopping is a function of physical forces, gravity and friction(Wright and Norman, 1976). 


\section{Factors That Determine Response Time}

Response time depends on several factors so there can be no single, universal reaction time value. Here is a list of factors, which affect reaction time.

\section{Urgency}

People brake faster when there is great urgency, when the time to collision is brief. The driver is traveling faster and/or the obstacle is near when first seen. While brake times generally fall with greater urgency, there are circumstances where reaction time becomes very long when time-to-collision is very short. The most common situation is that the driver has the option of steering into the oncoming lane in order to avoid the obstacle. The driver must consider alternative responses, braking vs. steering, weight the dangers of each response, and check the left lane for traffic(Green, 2000).

Age

Although most basic research finds that older people respond slower than younger ones, the data on older drivers' braking times are not entirely clear. One problem is that different studies have used different definitions of older; that is, sometime older means 55 and it could mean 70. Moreover, some studies find no slowing of reaction time with age. Instead, they conclude that the older driver's greater experience and tendency to driver slower compensate all or in part for the decline in motor skills(Green, 2000).

\section{Nature Of The Signal}

The driver detects a distinct signal such as a brake light and the appearance of a clear obstacle in the path. Some braking cues are subtle and more difficult to detect, causing slower braking times. One of the most difficult situations is when a driver detects motion of the car immediately ahead, its acceleration or deceleration. Accidents frequently occur because the driver fails to notice that the car ahead has stopped and does not apply brakes until it is too late(Well, 1976).

Secondly, normal expectation is that cars do not stop in the middle of the road. Reaction time, as explained above, is much slower when people encounter a low probability or unexpected event (Ball et al, 1993).

\section{Visibility}

Reaction time increases in poor visibility, low contrast, peripheral viewing and bad weather, which contribute to slow response. Moreover, virtually all reaction time studies have been performed in high light and photo pic visibility conditions. At night, in urban areas, vision operates in the myopic range, so there is mixed rod-cone activation. The few existing data suggest that reaction time sharply increases, as the rods become the primary photoreceptor. On the other hand, there are some situations in which response is faster in low light. For example, light emitting sources, such as rail-highway crossing signals or brake lights, produce better reaction times at night. With no sun or skylight to reflect off the fixture and with a darker background, the signal has higher contrast and greater visibility(Ball et al, 1993).

\section{Data Collection}

The intention is to enumerate the various data and respective method employed in relation to the study. It essentially addresses the driver's response time in traffic streams at Challenge Intersection, Ilorin.

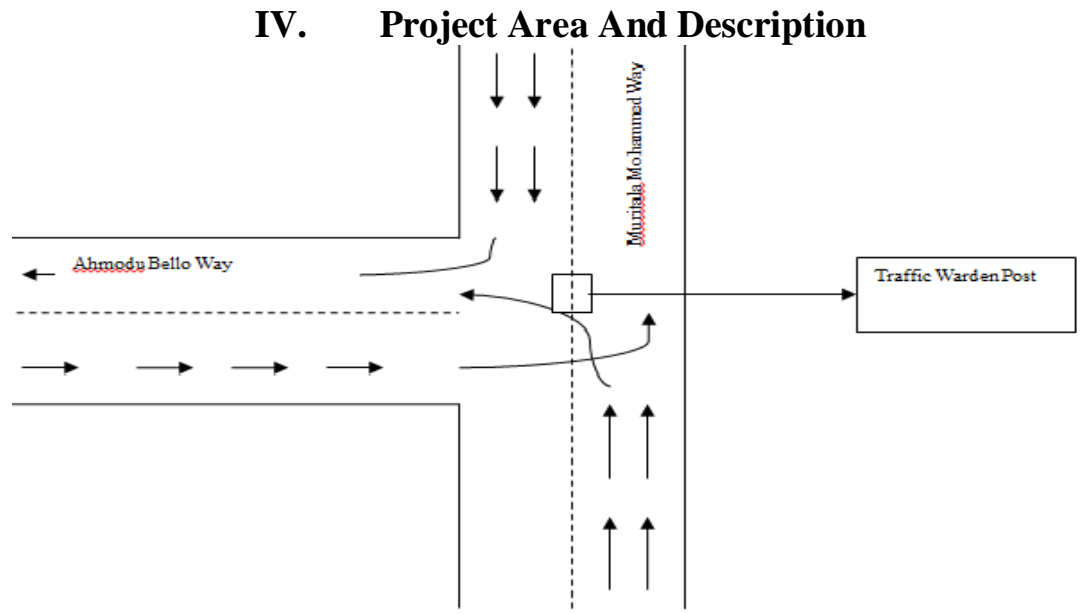

Figure 1.0 Sketch Location of Challenge Intersection 
The study location is at Challenge Intersection of Ilorin, Kwara State, Nigeria. It is a T- intersection consisting of three legs in which the minor leg was taken into consideration during the driver's perception reaction time measurement.Figure 1 shows the schematic presentation of the studied junction. The main type of traffic control in use is the traffic warden.

\section{Methodology}

The method employed was basically manual whereby stopwatches were used to measure the response times of drivers who were unaware of being monitored. The study recorded the response time of the warden's stop signal and the response time of the warden's move signal. The stopwatches were adopted in this project because of its inexpensiveness. The minor road affects the effective flow of the major roads, hence the minor road was analyzed in terms of the drivers' response time. The key parameters taken with the stopwatch were:

(1) Starting time when the traffic warden signals to stop or move.

(2) Response times that were displayed by the stopwatch when vehicle stops or moves.

\section{Procedure}

Measurements were made on a manual basis for a period of twelve hours (12hours) beginning from $7.00 \mathrm{a} . \mathrm{m}$ to $7.00 \mathrm{pm}$ at an hourly interval for seven days. Three observers were positioned where they had a clear view of the traffic. The queue lengths for each time sequence of the traffic warden controls were noted, during each hour of the study and during each cycle.

Several streams were considered; twenty runs for an hour of peak period were analyzed, the tables were graphically presented in order to infer their patterns. Measurements were made in three partitions and two runs were taken from each partition for analyzing and comparison. Also, the headways for the various vehicles (and indirectly, the drivers) were noted.

\section{Data Analysis}

Based on the data collected, the response times of the driver waiting to be served at the intersection were determined from which the headways were calculated. Also, mean, standard deviation and graphical representation of headways were used for analysis.

Time headway $(\mathrm{h})=\mathrm{T}_{2}-\mathrm{T}_{1}$

Where:

$\mathrm{T}_{2}=$ Time headway for the second vehicle

$\mathrm{T}_{1}=$ Time headway for the first vehicle

Mean $(\overline{\mathrm{X}})=\sum \frac{X}{N}$

$\operatorname{Variance}\left(\sigma^{2}\right)=\left(\frac{\Sigma(\mathrm{X}-\overline{\mathrm{X}})^{2}}{\mathrm{~N}-1}\right)$ and Standard deviation $=\sqrt{\operatorname{Var}\left(\sigma^{2}\right)}$

Where:

$\Sigma$ is called Sigma, means sum up

$\overline{\mathrm{X}}=$ Mean

$\mathrm{X}=$ Headway of each vehicle

$\mathrm{N}=$ Total number of vehicles per run

\section{Graphical Representation}

Figures 1.1- 1.7 show the graphical relationship of the headway against vehicles and tables $1.0-1.1$ show average headway to stop (headway 1 ) and move (headway 2)

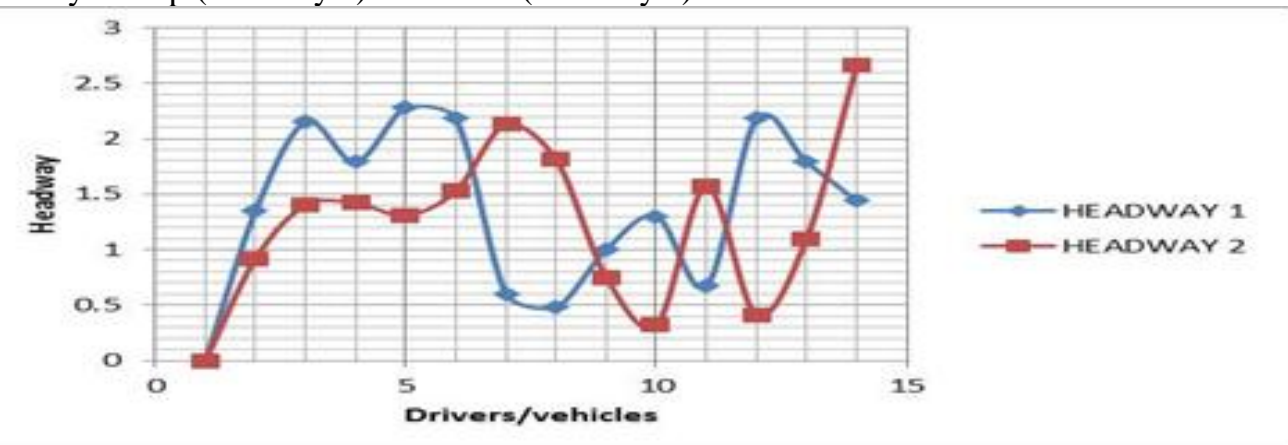

Figure 1.1 Headway against vehicles for day one 


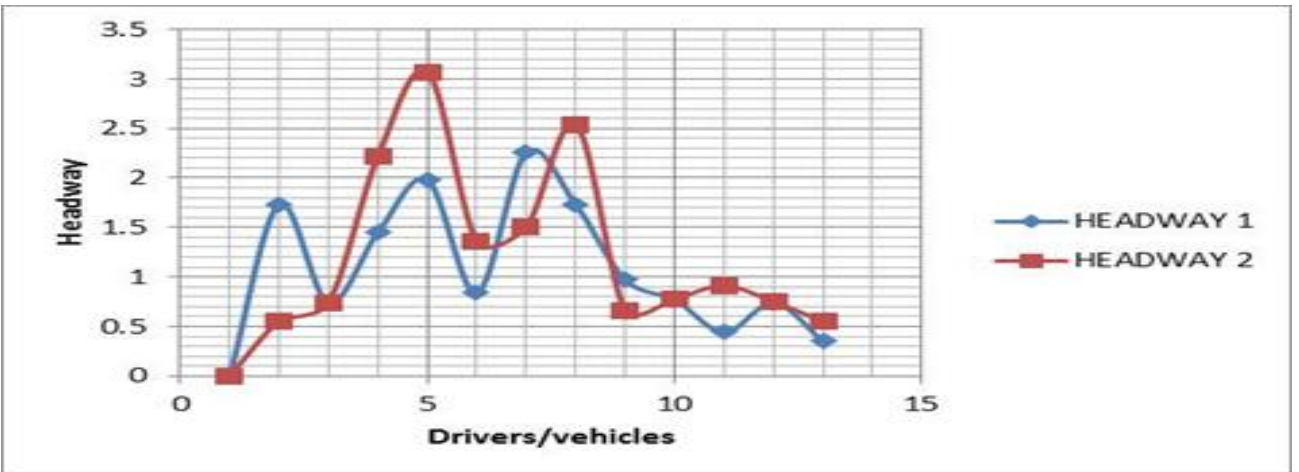

Figure 1.2 Headway against vehicles for day two

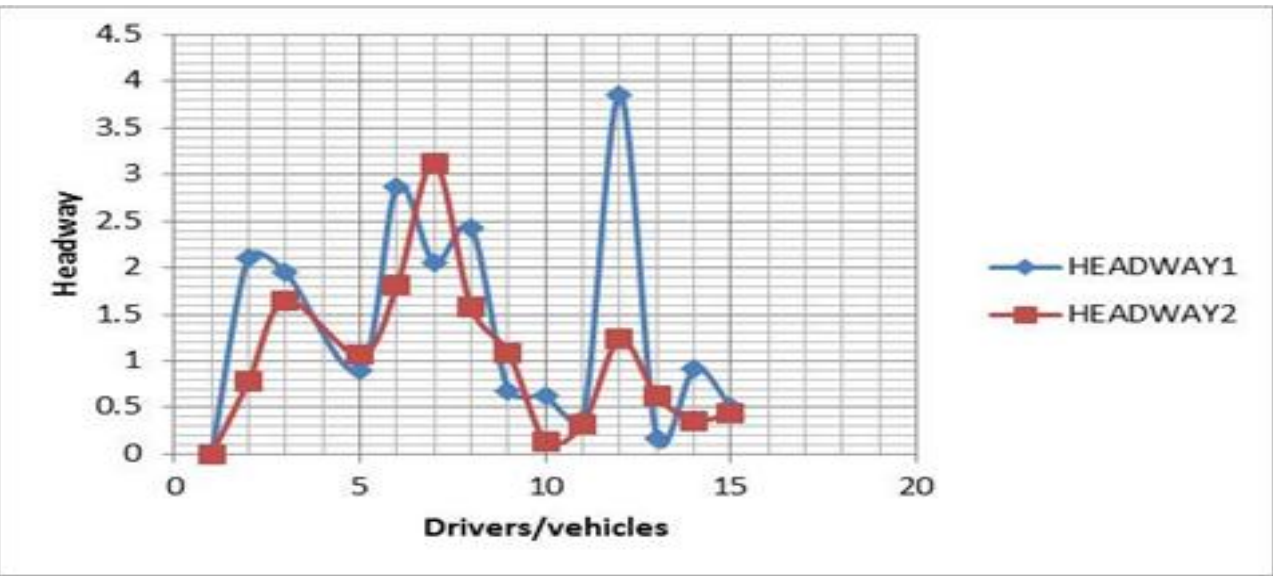

Figure 1.3 Headway against vehicles for day three

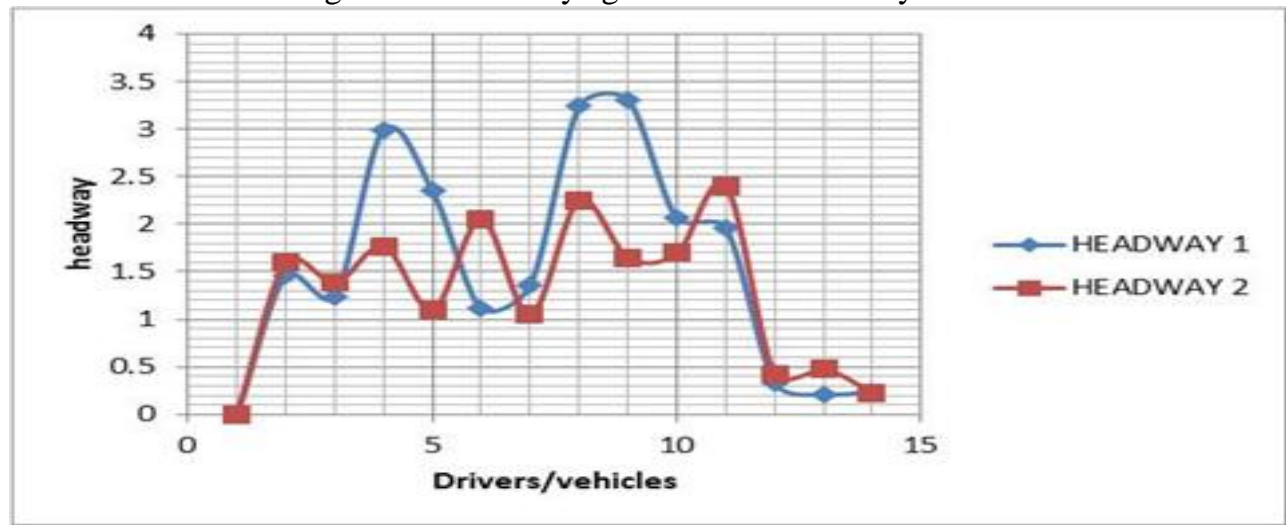

Figure 1.4 Headway against vehicles for day four

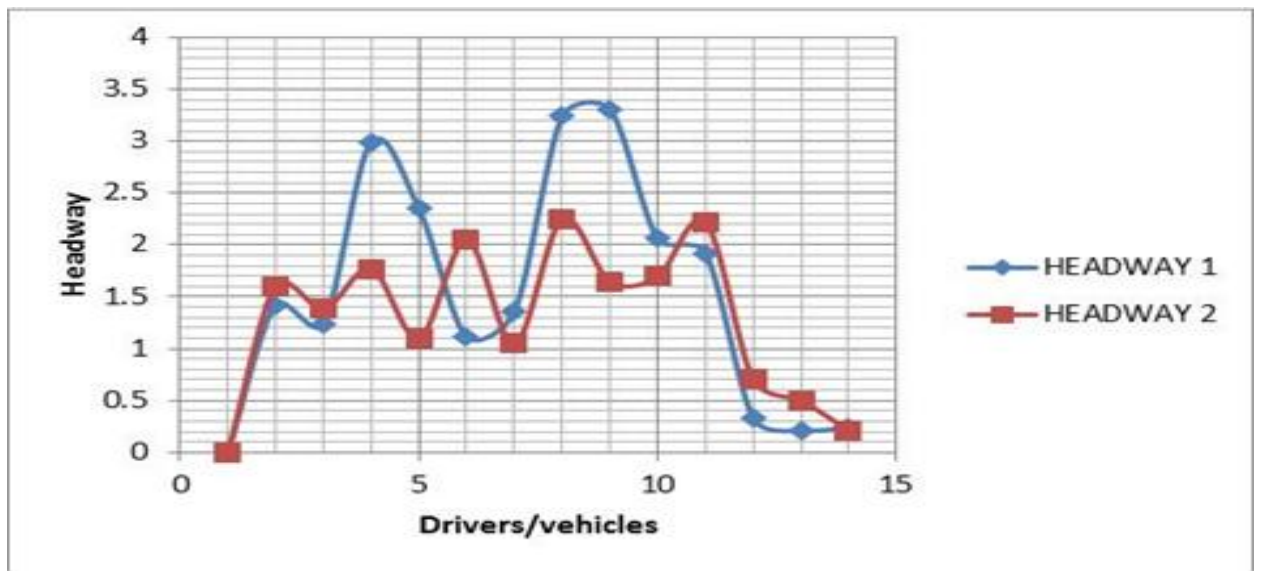

Figure 1.5 Headway against vehicles graph for day five 


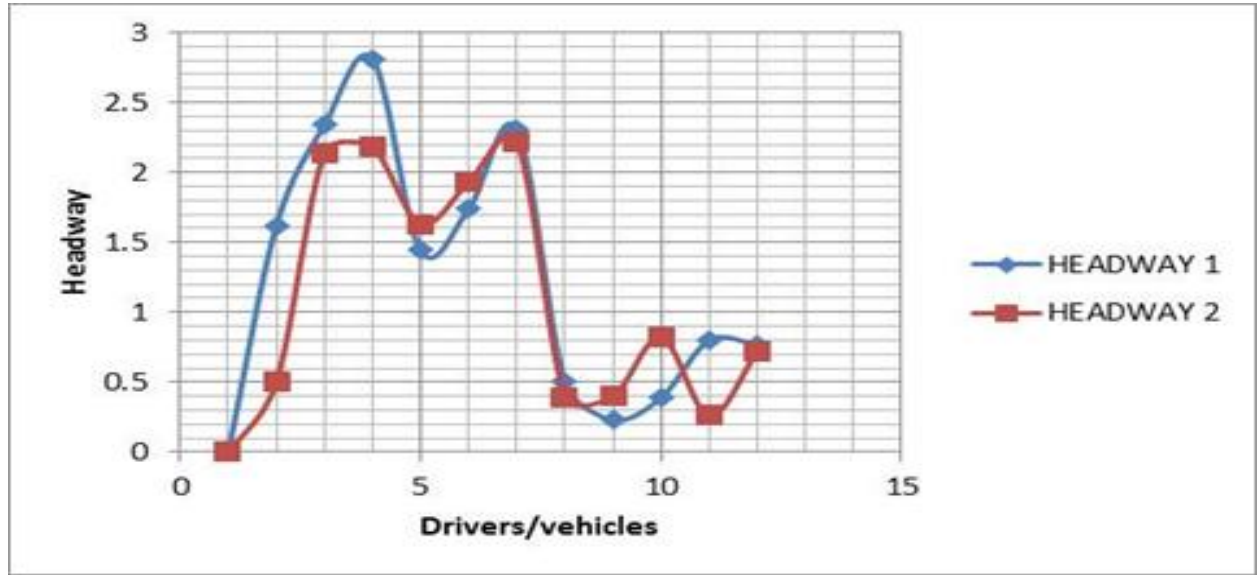

Figure 1.6 Headway against vehicles for day six

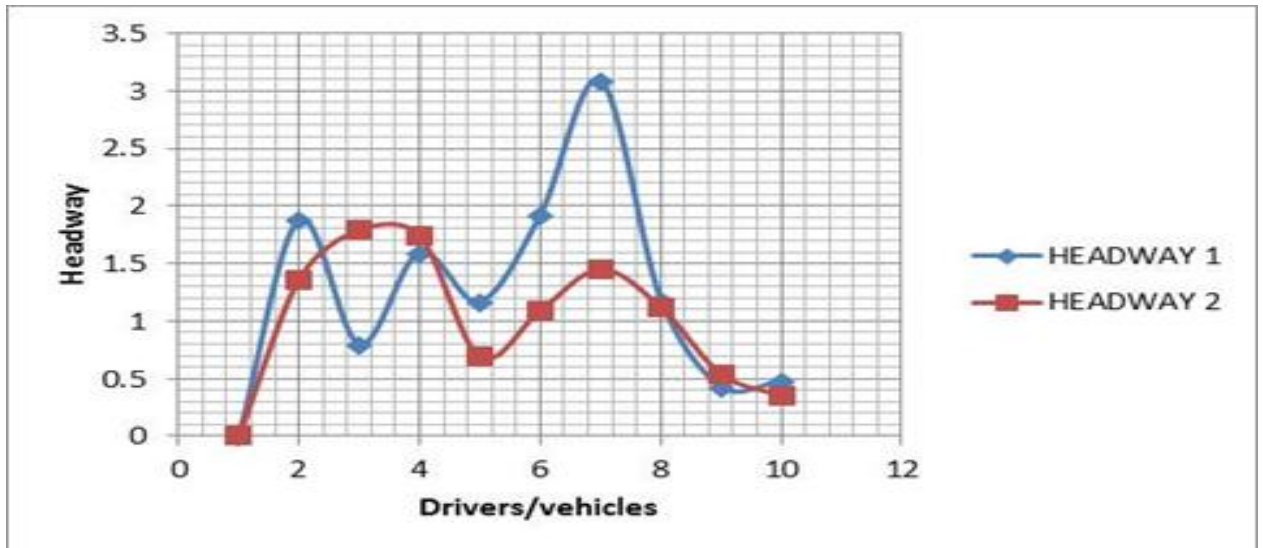

Figure 1.7 Headway against vehicles for day seven

Table 1.0 Average headway for the car to stop (minutes)

\begin{tabular}{|l|c|c|c|c|c|c|c|}
\hline Mean & 1.372143 & 1.076923 & 1.389286 & 1.561429 & 1.555714 & 1.245833 & 1.256753 \\
\hline $\begin{array}{l}\text { Standard } \\
\text { deviation }\end{array}$ & 0.733822 & 0.688602 & 1.157288 & 1.137817 & 1.137106 & 0.929129 & 0.906387 \\
\hline
\end{tabular}

Table 1.1 Average headway for the car to move (minutes)

\begin{tabular}{|l|c|c|c|c|c|c|c|}
\hline Mean & 1.237857 & 1.203077 & 1.014286 & 1.291429 & 1.298571 & 1.099167 & 1.013675 \\
\hline $\begin{array}{l}\text { Standard } \\
\text { deviation }\end{array}$ & 0.724528 & 0.899337 & 0.837585 & 0.767512 & 0.728105 & 0.850919 & 0.60137 \\
\hline
\end{tabular}

\section{Discussion Of Results}

In figures 1.1 to 1.7 , fifteen (15) was the highest number of vehicles served at the intersection in a single queue at any given time for a week and 889 vehicles were served per run in a week. The graphs of headway against vehicles were sinusoidal graphs. Towards the end of the graph, the signal has little response on those vehicles far behind. They do not need to see the traffic signal before they stop.

\section{Conclusion And Recommendation}

The morning peak periods vary between 8:00am and 10:00am while the morning lull period is between 11:00am and 12noon.The afternoon peak periods vary between 2:00 pm and 4:00pm and the afternoon lull period is between 6:00pm and 7:00pm.

The headway for a car to stop is more than the headway to move as shown in tables 1.0 and 1.1. The mean and the standard deviation for the headway to stop are 1.37 minutes and 0.73 minutes respectively. The values 1.23 minutes and 0.72 minutes are the mean and standard deviation for cars to move.

A comparative analysis can only be done once a signalized intersection is installed and a similar study be conducted using the same case study. Hence, one will be able to determine the most efficient and effective mode of traffic control between signalized and unsignalised intersection. 


\section{References}

[1]. AASHTO. 2001. A Policy On Geometric Design of Highways And Streets, American Association of State Highway and Transportation Officials, Washington, D.C.

[2]. Akcelik, A. A. 1999. Highway Capacity Manual (HCM) Glossary of Traffic Terms.

[3]. Ball, K., Owsley, C., Sloane, M. E., Roenker, D. L. and Bruni, J. R. 1993. Visual attention problems as a predictor of vehicle crashes in older drivers. Investigative Ophthalmology Visual Science. 34, pp. 3110-3123.

[4]. Garber, N. J. and Hoel, A. L. 1999. Traffic and Highways Engineering, Revised Second Edition.

[5]. Green, M. 2000. Methodological Analysis of Driver Perception Brake Times, Transportation Human Factors, Vol. 2, pp. 195 - 216.

[6]. Hobbs, F. D. 1974. Traffic planning And Engineering, Pergamon Press Ltd, Headington Hill Hall, Oxford.

[7]. Smith, D. 2002. Handbook of Simplified Practice for Traffic Studies, Iowa DOT Project TR -455,CTRE Project 01-80.

[8]. Vonk, K. D. 2007. Police Performance Under Stress.

[9]. Available:http://www.loukatactical.com/articles/Heart_Rate_and_Performance_Under_Stress_Article_to.pdf.

[10]. Well, J. 1976. Introduction to Traffic Engineering, Vol 4. Macmillan Printers.

[11]. Wright, P. H. and Norman, J. A. 1976. Traffic and Highway Engineering (Revised 2nd Edition), Stallion, Publication, Oakland, Ireland. 